\title{
ПРИОБРЕТЕНИЕ ПРАВ НА ЗЕМЕЛЬНЫЙ УЧАСТОК НА ОСНОВАНИИ ПРИОБРЕТАТЕЛЬНОЙ ДАВНОСТИ В ГЕОИНФОРМАЦИОННОМ АСПЕКТЕ
}

\author{
Дарья Васильевна Пархоменко \\ Сибирский государственный университет геосистем и технологий, 630108, Россия, г. Ново- \\ сибирск, ул. Плахотного, 10, доцент кафедры кадастра и территориального планирования, \\ тел. (913)900-19-50, e-mail: dara8@inbox.ru
}

\section{Ольга Александровна Горбунова}

Сибирский государственный университет геосистем и технологий, 630108, Россия, г. Новосибирск, ул. Плахотного, 10, обучающийся, тел. (952)909-09-39, e-mail: olya0356@gmail.com

В статье рассматривается проблема возникновения прав на земельный участок на основании приобретательной давности, а так же исследуются способы, с помощью которых возможно подтвердить давность существования границ земельного участка в определенных координатах.

Ключевые слова: земельный участок, границы, приобретательная давность, право собственности, государственная собственность на землю, презумпция государственной собственности на землю

\section{GEOINFORMATION ASPECT OF LAND PLOT RIGHTS ACQUISITION BASED UPON THE ACQUISITIVE PRESCRIPTION}

\section{Daria V. Parkhomenko}

Siberian State University of Geosystems and Technologies, 10, Plakhotnogo St., Novosibirsk, 630108, Russia, Ph. D., Associate Professor, Department of Cadaster and Territorial Planning, phone: (913)900-19-50, e-mail: dara8@inbox.ru

\section{Olga A. Gorbunova}

Siberian State University of Geosystems and Technologies, 10, Plakhotnogo St., Novosibirsk, 630108, Russia, Student, phone: (952)909-09-39, e-mail: olya0356@gmail.com

The article discusses the problem of the emergence of rights to a land plot on the basis of acquisitive prescription, and also examines the methods by which it is possible to confirm the prescription of the existence of the boundaries of a land plot in certain coordinates.

Keywords: plot, boundaries, acquisitive prescription, the property right, state ownership the land plot, a presumption of state ownership on the land plot

Одна из главных характеристик земельного участка - его границы. Они определяют конфигурацию такого объекта недвижимости. Процедура установления границ земельного участка заключается в определении поворотных точек и их координат с помощью геодезической съемки. Они фиксируются Росреестром и признаются официальными границами земельного участка, что подтверждается выпиской из Единого государственного реестра недвижимости (ЕГРН).

Целью настоящей статьи является рассмотрение такого основания приобретения права как преобретательная давность в отношении земельного участка и анализ способов для ее решения. 
Для достижения этой цели необходимо выполнить следующие задачи:

- обобщение проблематики определения давности существования границ земельного участка;

- анализ способов определения давности существования антропогенных и природных объектов, устанавливающих границы земельного участка (ЗУ).

Поворотные точки ЗУ должны иметь обозначение на местности, юридически оно закрепляется посредством определения геодезических координат в ЕГРН.

В случае, когда характерные точки не имеют юридического закрепления и их координаты не зафиксированы в ЕГРН, необходимы процедуры установления границ. В этом случае производится анализ имеющейся документации, которая, как правило, представлена одним из документов, описанных в таблице. Цель использования документа в этом случае - доказать, что поворотные точки юридически должны быть установлены так, как они условно закреплены на местности [1].

Документы, которые подтверждают существование границ земельных участков на местности

\begin{tabular}{|l|l|}
\hline \multicolumn{1}{|c|}{ Наименование документа } & \multicolumn{1}{|c|}{ Характеристика этого документа } \\
\hline $\begin{array}{l}\text { Правоустанавливающие, право- } \\
\text { подтверждающие документы на } \\
\text { 3У }\end{array}$ & $\begin{array}{l}\text { Содержат доказательства возникновения прав на владе- } \\
\text { ние, пользование и (или) распоряжение 3У. }\end{array}$ \\
\hline $\begin{array}{l}\text { Материалы картографических, } \\
\text { топографических съёмок }\end{array}$ & $\begin{array}{l}\text { Карты земной поверхности, позволяющие определять } \\
\text { плановое и высотное положение изображенных на ней } \\
\text { пространственных объектов в установленных проекциях, } \\
\text { системах координат и высот. }\end{array}$ \\
\hline Фотопланы местности & $\begin{array}{l}\text { Фотографическое изображение местности, отвечающее } \\
\text { требованиям контурного плана. }\end{array}$ \\
\hline $\begin{array}{l}\text { Картографические материалы } \\
\text { (планы, отводы и т.д.). }\end{array}$ & $\begin{array}{l}\text { Документ с информацией о местности, который может } \\
\text { быть использован для создания или обновления карты. }\end{array}$ \\
\hline
\end{tabular}

Случаи, когда необходимо установление границ земельного участка представлены на рис. 1.

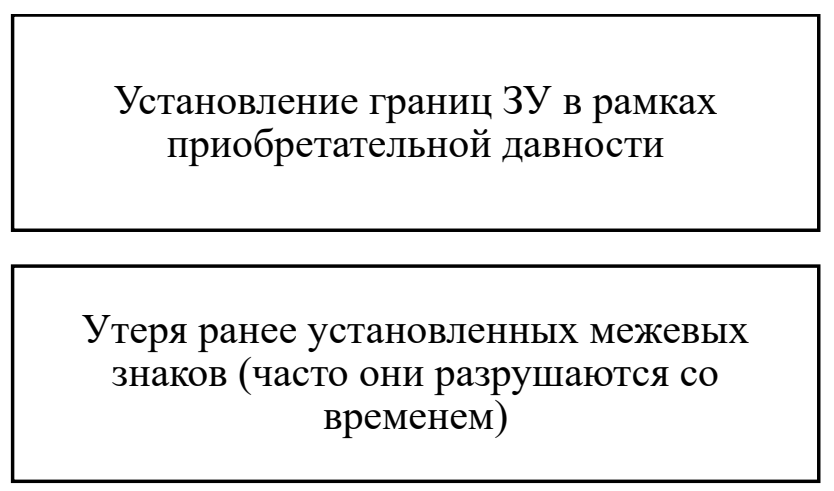

Приведение документов в соответствие с требованиями закона для исключения рисков оспаривания границ или площади участка в будущем

Конфликты с соседями по поводу границ участков

Рис. 1. Случаи, когда необходимо установление границ земельного участка с условием что осуществлялось пользование таким $3 У$ 
В данной статье рассматривается индивидуализация ЗУ в контексте признания прав на него на основании приобретательной давности.

Согласно п. 1 ст. 234 Гражданского кодекса в случае использования недвижимого имущества добросовестно, открыто и непрерывно в течение 15-ти лет после истечения срока исковой давности (итого 18 лет) может приобрести право собственности на это имущество на основании приобретательной давности [2]. В то же время суды [3] указывают на то, что в силу приобретательной давности права на ЗУ приобрести нельзя по двум причинам. Во-первых, в связи с презумпцией государственной собственности, в силу которой вся земля в любом случае принадлежит государству, во-вторых, не имеется возможности идентификации границ (и, как следствие, индивидуализации) ЗУ. Таким образом, основная проблема, как видится, состоит в том, что нет возможности определить геоинформационные данные ЗУ и установить время его использования [3].

Представляется, что на сегодняшний день геоинформационная составляющая наук о Земле позволяет установить время использования границ 3У, чтобы в дальнейшем отстоять права на данный объект недвижимости. Так, решение данной проблемы видится:

- в использовании программных продуктов, отслеживающих динамику развития местности, таких как Google Earth;

- в формировании методик определения давности существования антропогенных и природных объектов, устанавливающих границы ЗУ.

Программные продукты (на примере Google Earth) позволяют просматривать спутниковые снимки Земли с различных ракурсов. В данном приложении, имеются не только актуальные данные, но и данные за прошедшие года. А это значит что проблема «не возможности идентификации границ ЗУ» отходит на второй план, потому что данное приложение дает возможность заглянуть на состояние местности с 2003 года.

В ходе работы было исследовано приложение Google Earth, и рассмотрен ЗУ на территории города Новосибирска, расположенный по адресу ул.30 лет Октября, дом 20 [4]. Если было бы необходимо установить местоположение границ этого участка по состоянию 17 лет назад, это было бы возможно (рис. 2).

Исходя из публичной кадастровой карты (ПКК) и приложения Google Earth, были отмечены и закреплены поворотные точки выбранного земельного участка $[5,6]$. После чего во вкладке «Вид» подключены «Исторические снимки» и как можно дальше уведен временной ползунок. Для данной территории снимок 2003 года является крайним, но уже с использованием этих данных можно отстаивать свои права на данный участок, если бы это того требовало.

В 2021 году такие снимки будут отображать состояние местности 18 лет назад, что является веским аргументом для отстаивания прав владельца $3 У$ [7].

Следует обратить внимание на то, что если сегодня можно найти изъяны в представленной системе, связанные с точностью определения координат (10 см для городской территории), с некачественными съемками ранних лет, 
с отсутствием некоторых фрагментов съемки той или иной территории. Но в перспективе ближайших лет эти проблемы будут иметь все более выраженное решение, поскольку уже сегодня техника по производству съемок имеет определенный уровень.

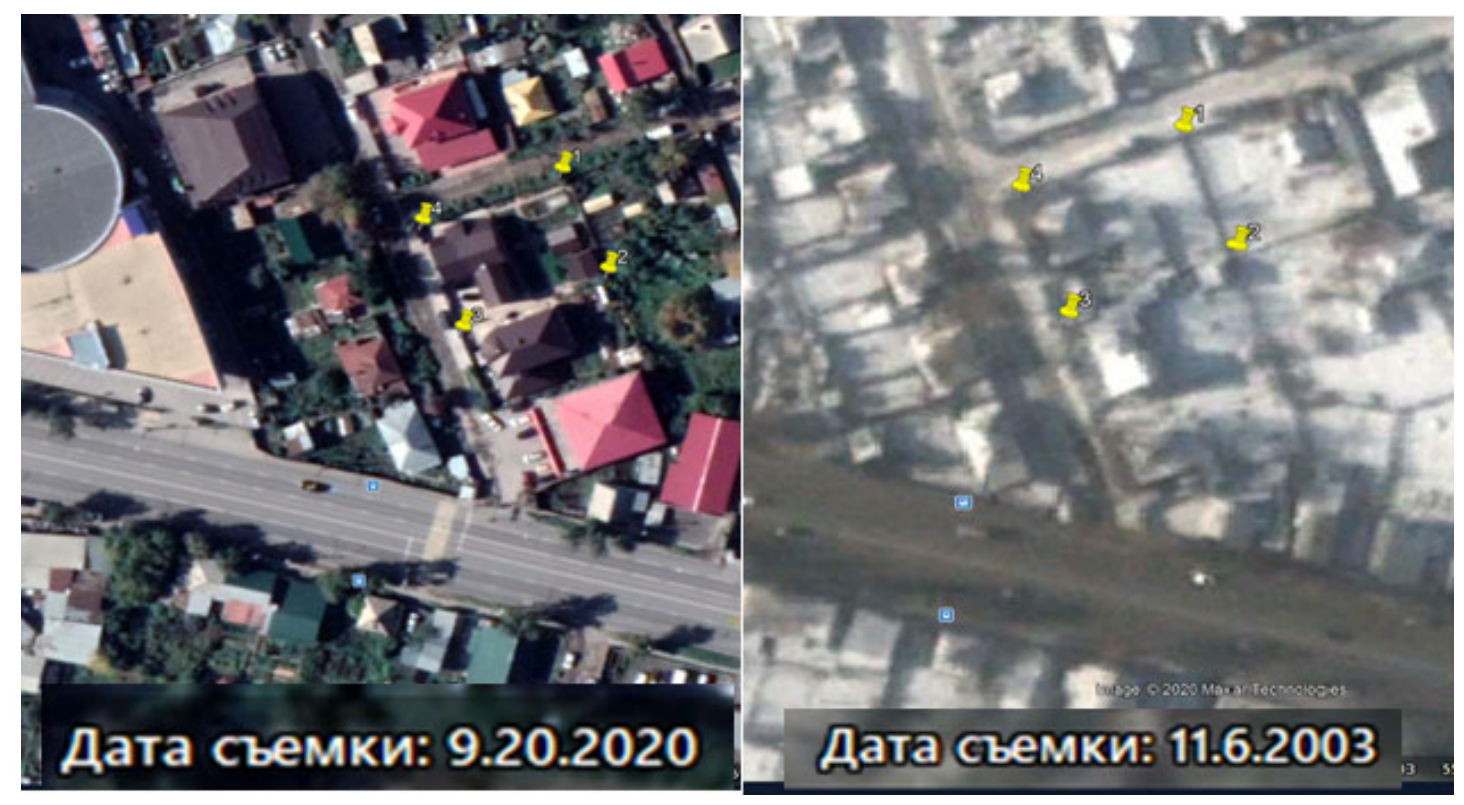

Рис. 2. Слева съемка, датированная 2020 годом, а справа 2003 года

Более сложным представляется способ формирования методик определения давности существования антропогенных и природных объектов, устанавливающих границы ЗУ.

Основная суть способа установления давности границ ЗУ с помощью антропогенных объектов заключается в том, что для доказательства давности существования границ на местности исследуются объекты, возведенные руками человека, которыми предположительно закреплен ЗУ. И по степени его «старения», разложения материала из которого изготовлен тот или иной объект, к примеру, забор, следует выявлять его время службы (возраст). Примерно таким же способом возможно исследование природных объектов. Например, может быть исследован «возраст» дерева. Так, исследует процесс старения хвойных деревьев: как он меняется с течением времени, какие новые особенности приобретает этот объект.

Данные методики находятся в стадии разработки авторов, и их стоит изучить более детально.

В данной статье была рассмотрена проблематика преобретательной давности в отношении земельного участка и представлены способы для её решения. Так же были выполнены все поставленные задачи и сделаны выводы о возможности уже сегодня определять динамику развития местности и давность существования границ объектов с использованием приложений, таких как Google Earth. В настоящее время разрабатываются методик определения давности существования антропогенных и природных объектов, устанавливающих границы ЗУ. 


\section{БИБЛИОГРАФИЧЕСКИЙ СПИСОК}

1. Федоренко Ю.В. Проблемы индивидуализации ранее учтенных земельных участков: С. 149. Актуальные проблемы правотворчества и правоприменительной деятельности: Науч.практ. конф. (Иркутск, 13 ноября 2010 г.): Материалы. Иркутск: Изд-во Иркут. гос. ун-та, 2010.

2. "Гражданский кодекс Российской Федерации (часть первая)" от 30.11.1994 N 51-Ф3 (ред. от 31.07.2020).

3. Постановление Пленума Верховного Суда РФ N 10, Пленума ВАС РФ N 22 от 29.04.2010 (ред. от 23.06.2015) "О некоторых вопросах, возникающих в судебной практике при разрешении споров, связанных с защитой права собственности и других вещных прав".

4. Карпик А. П., Хорошилов В. С. Сущность геоинформационного пространства территорий как единой основы развития государственного кадастра недвижимости // Известия вузов. Геодезия и аэрофотосъемка. - 2012. - № 2/1. 1. - С. 134-136 . - ППархоменко Д. В Методы контроля и судебной экспертизы межевых планов // Известия вузов. Геодезия и аэрофотосъемка. - 2020. - Т. 64, № 1. 1. - С. 104-110.

5. Публичная кадастровая карта [Электронный ресурс] https://pkk.rosreestr.ru/\#/search/66.08075299999886,100.05436299999829/3/@d98n7zxh.

6. Google Earth [Электронный pecypc] https://www.google.com/intl/ru_ALL/earth/versions/.

7. Умеренко Ю.А. Возникновение права собственности на земельный участок по основанию приобретательной давности : проблемы практики // //Юрист. -2016. - № 23. - С. 18-23.

(ㄷ Д. В. Пархоменко, О. А. Горбунова, 2021 